\title{
Extra-curricular methods for improving the quality of the staff training in the university of civil engineering (psychological content)
}

\author{
Tatiana Magera ${ }^{1, *}$ \\ ${ }^{1}$ Moscow State University of Civil Engineering, Yaroslavskoe sh., 26, 129337 Moscow, Russia
}

\begin{abstract}
High technologies in architecture and construction change the world around. Professional trainings for the creators of the artificial environment (engineers and architects) have an effect on people's life but practically they don't take into account the human nature of the final user and his own psychological features. In this article there are presented the results of the psychological services in the University of civil engineering from 2006 to 2017 as extra-curricular methods for the general competences formation and development. There are also described the methods of works and their specifics, some difficulties and perspectives. There are explained the reasons for psychological service at the university of civil engineering. There are also taken into account the global risks and dangers affecting the study content of civil engineering.
\end{abstract}

\section{Introduction}

Federal state budgetary educational institution of higher education "National Research Moscow State University of Civil Engineering" (NRU MGSU) - the biggest Russian higher education construction institution. The contemporary world trends affect on the educational environment and they also serve as a source for changes of the university's strategic development [1].

The future of the construction belongs to the smart cities construction, the smart technologies implementation, the region management reforming, the improvement of the social and psychological environment in the city. But the global problems causing by dynamism including all aspects of human life require purposeful efforts for its solving [2]. According to the information from the Global Challenges Foundation among these problems are: interdependent threats of climatic changes, global ecological disasters, armed conflicts (including nuclear and other weapons of mass destruction) and extreme poverty [3]. The report of the World Economic Forum published on the forum's eve in Davos-2017 contains the list of key risks including ecological (climate change), social and economic (inequality growth, polarization of society), technological (failures in infrastructures operation, the growing unemployment rate and social instability as a result of the technologies development), cooperation risks (possibility restriction of the countries interaction in case of the global problems solution) [4]. Construction of the safe

\footnotetext{
${ }^{*}$ Corresponding author: mageratatiana@mail.ru
} 
environment for human activity is a key function of the engineer professional activity and it can't ignore the contemporary risks and the competences and willingness to design the viable artificial environment is already appear and keep developing during the study in the university.

\section{Materials and methods}

According to the Order No. 602 from July 11, 2010 by the Ministry of Education and Science of the Russian Federation the Program of higher education institution for 20102019 contains the explanation of the reforms reasons which includes the report of "the unconformity of the professional education branch to requirements of the real sector of the economy" (further - "Program") [5]. In the Program there are presented such priority directions of development (PDD) as, firstly, housing construction and architecture and, secondly, high technologies in construction and architecture (including design, construction, technical upgrade and exploitation of especially dangerous, technically difficult and unique objects) [5]. Additionally, the development of high technologies in construction and architecture is directly oriented to resolve the complex safety problem, to protect against terrorism and to strength the defence capability of Russia, and also to use such technologies in mass housing construction [5].

During implementation of the Program, there are regularly published the reports of the actual achieved results. So, by "The report from 2015 on the development program implementation by Federal State Budgetary Educational Institution of Higher Education "National Research Moscow State University of Civil Engineering" (further - "Report"), at the university there were carried out the actions to improve and upgrade the research, development and innovative activities for nine priority directions including "the environment quality improvement in complex construction site, taking into account architectural, town-planning, engineering, social and humanitarian aspects". Development of science, technologies and technique in the Russian Federation is carried out in six priority directions including "Safety and anti-terrorism actions". Besides, in this Report it is specified that "in September, 2015 there was signed the agreement of intent for the Innovative centre "Construction" branch creation with the head quarter in already existed research and development basis of NRU MGSU. The document was signed by the Minister of Education and Science of the Russian Federation, by the Minister of Construction and Housing and Communal Services of the Russian Federation and by the rector of NRU MGSU. The new centre main activities will be: promoting of effective engineering science development and also infrastructure formation for the balanced and sustainable sector of researches and development, training of new generation of experts with relevant competences. The innovative centre is designed to become the main development centre of the sector aiming to innovations generation, carrying out researches, implementation of designer's ideas in real projects" [6].

The mutually advantageous combination of needs of the modern urban economy and university trainings are the driving forces for city development. The contribution to highly professional engineers preparation is the best investment into the future. The direction "training of new generation of the experts with relevant competences" is implemented in two ways: within the study program, updating the current study plans of the lessons and within the extra-curricular training programs. In NRU MGSU we invite stydents to form a part of "Student council", "Youth centre", Inter-club "the Planet of MGSU". The Centre of psychological support and legal consultations (further - "Centre") with the department of social, psychological and legal communications of NRU MGSU was created in 2016 at the university. The experts from our centre develop the programs taking into account the requirements of the contemporary world trends and the construction sector specifics. In this 
case the training of the construction personal moves to a new qualitative level. The professional and general competences are received through the relevant experience in the conditions not limited to classroom lessons.

The data obtained in the empirical way laid the foundation for the organization of the Center as a special unit of the university and also for carrying out the researches aimed to study social and psychological competences of participants of the educational environment in the university of civil engineering: basic data, development dynamics, the process analysis of its psychological impact and conditions. The main psycho-diagnostic tools of the researched are the supplementary psychological methods of research (questioning, conversation, testing) and the investigation of the current and previous documentation of the Center.

Questioning are done in polyvariant form for the purpose to extend the variety of responses given by participants and to use the indirect questions allowing to avoid the responses which are a priori right in the public's eyes. The conversation exercise is expected to study a small group of people and the results of this exercised compare with the questioning data. The test is directed to study the emotional [7] and social competences (for example, "Diagnostics "of emotional intelligence" (N. Hall)", "A technique of social intelligence research by J. Gilford and M. Salliven"). The current and reporting documentation of the Centre as source of the actual material, includes the following parts: registration, registration and informative, registration and methodical and the psychologist's records. The specified methods, except documentation study, were applied among teachers and students during out of the Centre's activities (classes at the faculty of professional development, students events), as well as during the psychological consultations and trainings. In this article the author generalizes, analyses the accumulated experience, focusing on results of psychological activities at the university of civil engineering.

\section{Results}

The centre of psychological support and legal consultations of NRU MGSU sets the tasks for the university's strategy development. It is reasonable to investigate the demand of the services offered by the Centre to increase the Centre operational productivity. We have the huge experience of rendering the psychological support for the students and employers of the university. From 2006 for 2017 we can highlight the work of the psychologists within the certain sub department (Psychology and pedagogical centre (2008-2012) and Centre of psychological support and legal communications) and independent activities when psychological assistance was given as a component of the training program included to the personal teachers plan.

The psychological centre as separate sub department organizes special activities, for example, psychological consultation on a request, trainings (emotional competence, leadership, oratorical skill, public speech skill, self-presentation, etc.) and the learning practical training aimed to form and develop social and psychological competences. From 2006 to 2012 the attention of psychologists was focused on development of such programs as:

1. Program for the first-year students adaptation to the university educational environment (2011).

2. Program for the employees adaptation to new conditions of the professional pedagogical activity caused by reforms of the higher education in the Russian Federation (2011).

3. Stress resistance Program for the students, professors and other staff of the modern university (2012) 
4. Emotional competence Program for the professors of the higher educational institution (2010)

5. Emotional competence Program for students of higher education institution of civil engineering (2010)

6. Psychological unloading room work Program (2009)

7. Training Program for the internship preparation for the students-managers (20092017)

8. Team building training Program (2007-2016)

9. Self-presentation training Program (2011)

10. Training Program for the course "Teacher of the higher education institution" (2011)

11. Training Program for prospective university students "School of the professional orientation" (2009-2017)

12. Programs of trainings and work shops for school students within the project University Saturdays (2014-2017)

13. Adaptation training Program for orphan children (2011)

From all persons applied for the psychological services for the specified period, there were selected 3000 people, the main contingent - more than $50 \%$ - were students, about $30 \%$ - teachers and heads of different organizations from the Association of construction higher education institutions of the Russian Federation, including NRU MGSU and about $20 \%$ - exterior participants (prospective students, school students, parents). What features can be observed by results of the carried-out activity? Few of them can be formulated as follows.

\section{Discussion}

First, relevance of the psychological services in higher education institution of civil engineering and at the same time the complexity in case of applying and rendering such services. Only in three weeks of Centre's work there were held 55 events without any advertising and in the busy educational schedule condition caused by the final part of the semester. With a heavy workload and the mistrust to psychology noted in construction branch, only in rare cases $(0,4 \%$ (!) of the adults (from 22 years) participants) resistance of participants of the training group remained during all trainings on emotional competence to a final stage and summing up. Therefore, in case of the relevant intentions of the participants it was observed the readiness to join in training process with full responsibility. The readiness shows that the person has the interpersonal need. Of course, the image of the builder (and the teacher of higher education institution of civil engineering) has steady cold character of a purposeful expert or a leader without any possibility to test and (the more so) to show any irrational personal aspects (for example, impulsiveness, emotionality, sensitivity), thus, identifying himself with representatives of professional community. He keep doing his life style activity in stability not due to acceptance of own integrity and healthy self-updating, but thanks to exhaustible strong-willed qualities as self-possession and patience. But it is possible only on limited period. Without any constructive measures the further scenario of consequences has no opportunity to keep the life and health condition of builder and of his relevance at the correct level. The acceptance of an irrational part of our mentality which is capable to be self-government is already a step for saving our psycho-emotional health.

Secondly, there are typical features for various age groups of the Centre's activity participants. So, for example, in trainings on emotional competence, resisting, as a rule, the participants from 50 to 55 years are the most resistant. The life and working experience, the gained status become an unreasonable burden in a training situation, blocking the mental 
plasticity, sabotaging all new. The role of the psychologist-trainer, methodological and methodical training structure, maintenance of the atmosphere of a general purposeful and positive concentration serve as mechanisms to win through this resistance. Students as a group, thanks to access to information sources provided by Internet have some different segmental knowledge of popular scientific content. This kind of information provokes an interest in psychology, but also creates some additional filters for systematization of the scientific psychological knowledge (what is the "truth" and what is not), for psychological techniques and practice. In this case it is logical to include in the plan of the activity an exercise, aimed to divide scientific and everyday psychology.

Thirdly, the psychologist work in higher education institution is regulated by a wide range both opportunities, and the restrictions which are a consequence of the standard documentation regulating activities in the university. Educational process, research activities, social work are priority task for students and teachers. Disciplines of a psychological course are leaded by teachers-psychologists, together with students there are implemented psychological researches with the following publication of its results in scientific periodicals, the techniques developed within activities of the Centre are patented. On the other hand, the time for rendering psychological support become very limited that allows to correspond to the educational schedule, but complicates implementation of urgent programs of the Centre.

Fourthly, the reference points determining the relevance of Centre's various programs are displaced. The contemporary programs connected to requests from university managing bodies and transmits the modern policy of the state. If a few years ago this kind of the contemporary program was the adaptation to the changing educational environment, then today the most important subject is the is a safety program, including risks of terrorist threats. Another area of Centre activity is the psychological support for handicapped people [8]. It is important to note that regardless of external changes, the advisory and psychological practice (psycho-emotional self-control (stresses, fears, uneasiness, exhaustion, etc.) [9], the conflicts, self-knowledge, the child parent relations, selforganization ...) are still highly demanded.

Fifthly, the higher construction education tends to concentrate on technical disciplines today. The phrase "technical university" is aimed to underline construction specifics of educational process. The question "Why does engineer need Psychology (Psychologist)?" requires directs reasons. But if we look closer we can see that students of construction higher education institution have a lot of reasons to be interested in this scientific area. Outside a study of the psychological course disciplines in higher education institution there is a space of the demanded opportunities of the psychological support, unfortunately without the relevant realization. We should mark that creation of the comfortable urban environment is impossible without understanding of the contest of social and psychological comfort for citizens [10]. Various researches of different years confirms that anxiety of the citizens living in the cities of Russia doesn't decrease $[11,12]$. Experts say that any threat is the first of all, psychological influence expressing in fear, panic, lack of confidence in the quotidian life, mistrust to people around up to aggression and hate. Sustained anxious of the cities residents doesn't allow them to feel fully any changes of infrastructure, increasing of the service level due to the implementation of smart technologies to the urban environment. Finally, ignoring of psychological aspects during creation of the smart cities, affects the budget of the region because of the lack of the feedback the population which is negative or unspoken. The example with a psycho-emotional component of the urban environment construction is eloquent, properly it isn't explained in any technical discipline, and out of studies the psychological centre in construction higher education institution becomes compensating for such a gap. The prove of $t$ demand for Centre services is the separate request from the Institute of construction and architecture of NRU MGSU about the work 
content of the Centre for information of employees and students of the institute. Emotions are a human life background, so investigation of the human emotions nature will allow to make the building with high comfort level and to improve the territories conditions from the moment of design to a billboards placement stage.

\section{Conclusions}

Basing on the results of psychologists activities in higher education institution of civil engineering from the 2006, considering modern challenges endangering human life, the Centre activities for psychological support and legal consultations of NRU MGSU fully respond to the needs of educational process participants, it accords with policy of the state and takes into account global problems. The extra-curriculum format of Centre activities today depends a lot on the educational schedule and workload of teachers. Consultation of psychologists and lawyers is organized according to the schedule and on request of the applicant. It is free of charge. There are prepared the materials for development of programs for adaptation of the first-year students, including the trainings dedicated to terrorism counteraction; programs of psychological support for handicapped people; programs for training in psychological aspects of the artificial environment design; programs of self-government [13] and self-presentation trainings. All work is realized taking into account age and health conditions of the Centre activity participants; the study specialisation is taken into account as well.

The presence of Centre in the modern higher educational construction institution creates the important conditions for formation and development of the competences allowing to prepare not just engineering personal, but professionals who can build for people $[14,15]$. The engineer who directs by the needs of real people can improve the level of the life quality in the urban environment, low the level of the stress of citizens. And only the professional with high level of the emotional competence can avoid stress accumulation due his professional activity.

\section{References}

1. E.A. Shnyrenkov, I.P. Pryadko Procedia Engineering, 117, 325-330 (2015)

2. I.P. Pryadko, International Journal of Applied Engineering Research, 21, 42147-42152 (2015)

3. URL: https://globalchallenges.org/ru

4. URL: https://www.weforum.org/

5. URL: http://mgsu.ru/universityabout/04-06-ProgrammaRazvitiaMGSU.pdf

6. URL: http://mgsu.ru/universityabout/Programma_razvitia/OTCHET_NIU_MGSU_2015.pdf

7. Goulman, D. Emocionalny intellekt (AST, Moscow, 2009)

8. N.G. Miloradova, A.D. Ishkov, 3rd international multidisciplinary scientific conf. on social sciences \& arts, sgem-2016, Series «Fiinance. Economic and tourism», 811-818 (2016)

9. Khripko E. Matec web of conferences, 73, 07021 (2016)

10. M.G. Leontev, MATEC Web of Conferences. 7307005 (2016)

11. E. Romanova, Procedia Engineering, 165, 1176-1183 (2016)

12. M. K. Gorshkov, R. Krumm, V. V. Petukhov, Russia on a new turning point: fears and anxious (Alpha, Moscow, 2009) 
13. A.D. Ishkov, N.G. Miloradova, A.Yu. Chernyshev, Procedia - Social and Behavioral Sciences (2015). V. 171. Pp. 765-770.

14. Ishkov, A., Magera, T. Procedia Engineering, 117, pp. 148 - 153 (2015) http://dx.doi.org/10.1016/j.proeng.2015.08.251

15. O. Gamayunova, N. Vatin, AMM, 725-726, 1640-1645 (2015) 